\title{
Activated Carbon - ZnO Nanocomposite for Electrochemical Sensing of Acetaminophen
}

\author{
Mani Sivakumar, Mani Sakthivel, Shen-Ming Chen* \\ Electroanalysis and Bioelectrochemistry Lab, Department of Chemical Engineering and \\ Biotechnology, National Taipei University of Technology, Taipei 10608, Taiwan. \\ *E-mail: smchen78@ms15.hinet.net
}

doi: $10.20964 / 2016.10 .51$

Received: 25 June 2016 / Accepted: 15 August 2016 / Published: 6 September 2016

In this work, we reported the preparation of $\mathrm{AC}-\mathrm{ZnO}$ by using simple chemical co-precipitation and ultrasonication techniques and investicated the electrocatalytic behaviour of acetaminophen (ACP) at $\mathrm{AC}-\mathrm{ZnO}$ modifed glassy carbon electrode. Then, the as prepared $\mathrm{AC}-\mathrm{ZnO}$ was analyzed by using spectroscopy and electrochemical techniques such as Scanning Electron Microscopy (SEM), Cyclic Voltammetry (CV), Linear Sweep Voltammetry (LSV) and Amperometry method. Fortunately, AC$\mathrm{ZnO}$ modified glassy carbon electrode shows the better electrocatalytic behaviour towards ACP than $\mathrm{ZnO}-\mathrm{GCE}$ and AC-GCE. Finally, from the amperometric $i$ - $t$ curve the electrochemical parameters were calculated by varying the resultant linear response current with the concentration of ACP over the range from 0.05 to $1380 \mu \mathrm{M}$. In addition, the corresponding sensitivity and limit of detection (LOD) were calculated of about $8.33 \mu \mathrm{A} \mu \mathrm{M}^{-1} \mathrm{~cm}^{-2}$ and $0.83 \mu \mathrm{M}$ respectively. Eventually, the proposed $\mathrm{AC}-\mathrm{ZnO} / \mathrm{GCE}$ was found as the suitable materials with unique stability, repetability and reproducibility towards ACP sensor.

Keywords: $\mathrm{ZnO}-\mathrm{AC}$, acetaminophen, electrochemical sensor.

\section{FULL TEXT}

(C) 2016 The Authors. Published by ESG (www.electrochemsci.org). This article is an open access article distributed under the terms and conditions of the Creative Commons Attribution license (http://creativecommons.org/licenses/by/4.0/). 